\title{
PENGALAMAN PENDERITA GASTRITIS KRONIS DALAM MELAKUKAN TEKNIK RELAKSASI NAFAS DALAM UNTUK MEMBANTUMENURUNKAN SKALA NYERI PADA PENDERITA GASTRITIS KRONIS DI RUMAH SAKIT ISLAM SITI KHADIJAH PALEMBANG TAHUN 2019
}

\author{
Noviliya Hawati \\ Prodi S1Keperawatan STIKES Mitra Adiguna Palembang \\ Komplek Kenten Permai Blok J No.9-12 Bukit Sangkal Palembang 30114
}

\begin{abstract}
Abstrak
Menurut data WHO angka persentase kejadian gastritis di dunia, diantaranya Inggris 22\% , China 31\%, Jepang 14,5\%, Kanada 35\%, dan Prancis 29,5\%. Insiden gastritis di Asia Tenggara sekitar 583.635 dari jumlah penduduk setiap tahunnya.Penderita gastritis sering mengalami nyeri, untuk mengatasinya dapat dilakukan terapi non farmakologi berupa relaksasi nafas dalam yaitu teknik yang dilakukan untuk menekan nyeri pada thalamus yang dihantarkan ke korteks cerebri dimana korteks cerebri sebagai pusat nyeri, yang bertujuan agar pasien dapat mengurangi nyeri selama nyeri timbul.Tujuan penelitian ini adalah untuk mengetahui pengalaman penderita gastritis dalam melakukan teknik relaksasi nafas dalam untuk membantu menurunkan skala nyeri pada penderita gastritis kronis di Rumah Sakit Islam Siti Khadijah Palembang Tahun 2019.Metode penelitian yang digunakan adalah deskriptif kualitatif.Situasi sosial dalam penetian ini adalah 2 orang pasien gastritis kronis sebagai partisipan dan seorang informan kunci yaitu perawat yang bertugas di Rumah Sakit Islam Siti Khodijah Palembang.Hasil penelitian didapatkan bahwa pengalaman responden selama melakukan terapi relaksasi nafas dalam Tn.M dan Tn.K mengaku nyeri lambung yang dirasakan berangasur-angsur berkurang.Tn.M dan Tn.K melakukan terapi relaksasi nafas dalam setiap kali nyeri lambungnya kambuh.Saran diharapkan kepada petugas kesehatan di Rumah Sakit Islam Siti Khadijah Palembang, dapat meningkatkan pelayanan kepada pasien gastritis khususnya dalam membantu pasien mengatasi rasa nyeri.
\end{abstract}

Kata kunci $\quad$ : Pengalaman, gastritis, relaksasi nafas dalam

\section{Abstract}

According to WHO data the percentage incidence of gastritis in the world, including the UK $22 \%$, China 31\%, Japan 14.5\%, Canada 35\%, and France 29.5\%. The incidence of gastritis in Southeast Asia is around 583,635 of the total population each year. Gastritis sufferers often experience pain, to overcome this non-pharmacological therapy in the form of deep breathing relaxation is a technique used to suppress pain in the thalamus delivered to the cerebral cortex where the cerebral cortex is the center of pain, which aims so that patients can reduce pain during the pain arising. The purpose of this study is to determine the experience of gastritis sufferers in performing deep breathing relaxation techniques to help reduce pain scale in patients with chronic gastritis at Siti Khadijah Islamic Hospital Palembang in 2019. The research method used is descriptive qualitative. Social situations in this determination are 2 patients with chronic gastritis as participants and a key informant namely nurses on duty at the Siti Khodijah Islamic Hospital in Palembang. The results of the study found that the respondents' experience during $i$ do breath relaxation therapy in $M r . M$ and $M r . K$ claiming stomach pain that is felt gradually decreases. Mr. M. and Mr. $K$ do breathing relaxation therapy every time the stomach pain recurs. Suggestions are expected to health workers at Siti Islamic Hospital Khadijah Palembang, can improve services to gastritis patients, especially in helping patients deal with pain.

Keywords: Experience, gastritis, deep breath relaxation 


\section{PENDAHULUAN}

Salah satu organ terpenting dalam tubuh manusia yang digunakan bagi makhluk hidup sebagai penyimpan makanan yaitu lambung. Yang mana fungi lambung bagi tubuh yang paling utama adalah sebagai menerimamakanan dan bekerja sebagai penampung untuk jangka waktu pendek, semua makanan dicairkan dan dicampurkan dengan asam hirokiorida dan dengan cara ini disiapkan untuk dicerna olehusus. Selama kadar asam lambung dalam tubuh sesuai kadar normal tidak akan menyebabkan suatu gangguan atau penyakit,tetapi jika kadar asam lambung dalam tubuh berlebih akan menyebabkan nyeri perut/ gastritis (Putri, 2017).

Gastritis merupakan gangguan kesehatan yang paling sering dijumpai di klinik, karena diagnosisnya sering hanya berdasarkan gejala klinis bukan pemeriksaan histopatologi.Pada sebagian besar kasus inflamasi mukosa gaster tidak berkorelasi dengan keluhan dan gejala klinis pasien.Sebaliknya keluhan dan gejala klinis pasien berkorelasi positif dengan komplikasi gastritis. Gastritis merupakan suatu peradangan mukosa lambung yang disebabkan oleh kuman helicobakteri pylori yang dapat bersifat akut, kronik difus atau lokal (Hirlan dalam Angkow, 2016)

Badan penelitian kesehatan dunia

World Health Organization (WHO) mengadakan tinjauan terhadap beberapa negara dunia dan mendapatkan hasil dari angka persentase kejadian gastritis di dunia, diantaranya Inggris $22 \%$, China $31 \%$, Jepang 14,5\%, Kanada 35\%, dan Prancis 29,5\%. Insiden gastritis di Asia Tenggara sekitar 583.635 dari jumlah penduduk setiap tahunnya. Angka kejadian gastritis yang dikonfirmasi melalui endoskopi pada populasi di Shanghai sekitar 17,2\% yang secara substansial lebih tinggi daripada populasi di barat yang berkisar $4,1 \%$ dan bersifat asimptomatik (Tussakinah, 2017).

Persentase dari angka kejadian gastritis di Indonesia menurut WHO adalah
40,8\% dan angka kejadian gastritis di beberapa daerah di Indonesia cukup tinggi dengan angka kejadian 274.396 kasus dari 238.452.952 jiwa penduduk. Berdasarkan profil kesehatan Indonesia tahun 2011, gastritis merupakan salah satu penyakit dari 10 penyakit terbanyak pada pasien rawat inap di rumah sakit di Indonesia dengan jumlah 30.154 kasus (4,9 \%). Berdasarkan data Dinas Kesehatan Provinsi Sumatera Barat, gastritis menempati urutan ke-3 dari 10 penyakit terbanyak di Sumatera Barat tahun 2014 yaitu sebesar 86.874 kasus (10,94\%) (Tussakinah, 2017).

Dari data dinas kesehatan Provinsi Sumatera Selatan diketahui bahwa jumlah penyakit gastritis pada tahun pada tahun 2013 didapat angka kejadian gastritis sebanyak 63.408 kasus, sedangkan pada tahun 2014 sebanyak 52.936 kasus dan pada tahun 2015 sebanyak 49.115 kasus (Sunarmi, 2018).

Dari data dinas kesehatan kota Palembang diketahui bahwa penderita penyakit gastritis pada tahun 2016 sebanyak 48.162 orang, tahun 2017 sebanyak 49.115 orang dan tahun 2018 sebanyak 54.159 orang (Dinas Kesehatan Kota Palembang, 2019).

Faktor risiko gastritis adalah menggunakan obat aspirin atau anti-radang non steroid, infeksi kuman helicobacter pylori, memiliki kebiasaan mengkonsumsi minuman beralkohol, memiliki kebiasaan merokok, sering mengalami stres, pola makan yang tidak teratur serta terlalu banyak mengkonsumsi makanan yang pedas dan asam. Selain itu Orang yang memiliki pola makan tidak teratur, mudah terserang penyakit ini. Pada saat perut harus diisi, tapi dibiarkan kosong, atau ditundanya pengisian, asam lambung akan mencerna lapisan mukosa lambung, karena ketika kondisi lambung kosong, akan terjadi gerakan peristaltik lambung bertambah intensif yang akan merangsang peningkatan produksi asam lambung sehingga dapat timbul rasa nyeri diulu hati (Angkow, 2016). 
Rasa nyeri merupakan stresor yang dapat menimbulkan stress dan ketegangan dimana individu dapat berespon secara biologis dan perilaku yang menimbulkan respon fisik dan psikis. Respon fisik meliputi perubahan keadaan umum, wajah, denyut nadi, pernafasan, suhu badan, sikap badan, dan apabila nafas makin berat dapat menyebabkan kolaps kardiovaskuler dan syok, sedangkan respon psikis akibat nyeri dapat merangsang respon stress yang dapat mengurangi sistem imun dalam peradangan, serta menghambat penyembuhan respon yang lebih parah akan mengarah pada ancaman merusak diri sendiri (Corwin dalam Ayudianingsih, 2015).

Manajemen nyeri merupakan salah satu carayang digunakan dibidang kesehatan untuk mengatasi nyeri yang dialami oleh pasien. Pemberian analgesik biasanya dilakukan untuk mengurangi nyeri. Teknik relaksasi merupakan alternatif non obatobatan dalam strategi penanggulangan nyeri, disamping metode TENS (Transcutaneons Electric Nerve Stimulation), biofeedack, plasebo dan distraksi. Relaksasi merupakan kebebasan mental dan fisik dari ketegangan dan stress, karena dapat mengubah persepsi kognitif dan motivasi afektif pasien. Teknik relaksasi membuat pasien dapat mengontrol diri ketika terjadi rasa tidak nyaman atau nyeri, stress fisik dan emosi pada nyeri (Potter \& Perry dalam Ayudianingsih, 2015).

Teknik relaksasi nafas dalam adalah teknik yang dilakukan untuk menekan nyeri pada thalamus yang dihantarkan ke korteks cerebri dimana korteks cerebri sebagai pusat nyeri, yang bertujuan agar pasien dapat mengurangi nyeri selama nyeri timbul. Adapun hal-hal yang perlu diperhatikan saat relaksasi adalah pasien harus dalam keadaan nyaman, pikiran pasien harus tenang dan lingkungan yang tenang. Suasana yang rileks dapat meningkatkan hormon endorphin yang berfungsi menghambat transmisi impuls nyeri sepanjang saraf sensoris dari nosiseptor saraf perifer ke kornu dorsalis kemudian ke thalamus, serebri, dan akhirnya berdampak pada menurunnya persepsi nyeri (Brunner \& Suddart dalam Ayudianingsih, 2015).

Pengalaman merupakan peristiwa yang tertangkap oleh panca indera dan tersimpan dalam memori. Pengalaman dapat diperoleh ataupun dirasakan saat peristiwa baru saja terjadi maupun sudah lama berlangsung. Pengalaman yang terjadi dapat diberikan kepada siapa saja untuk digunakan dan menjadi pedoman serta pembelajaran manusia. (Notoatmojo dalam Saparwati, 2012).

Berdasarkan hasil penelitian Rampengan (2014) yang berjudul pengaruh teknik relaksasi dan teknik distraksi terhadap perubahan intensitas nyeri pada pasien post operasi di Ruang Irina A Atas RSUP Prof. Dr.R.D Kandou Manado. Hasil penelitian terhadap 15 responden sebelum dilakukan teknik relaksasi didapatkan hasil sebagian besar responden mengalami intensitas nyeri lebih nyeri yaitu sebanyak 6 orang (40\%), intensitas nyeri sedikit lebih nyeri sebanyak 4 orang $(26,7 \%)$, intensitas nyeri sangat nyeri 3 orang $(20 \%)$ dan intensitas nyeri sedikit nyeri sebanyak 2 orang $(13,3 \%)$. Setelah dilakukan teknik relaksasi, sebanyak 2 responden menyatakan tidak mengalami nyeri dan tidak ada responden yang mengalami intensitas nyeri sangat nyeri dan intensitas nyeri lebih nyeri.

Berdasarkan yang didapat dari Rumah Sakit Islam Siti Khadijah Palembang, jumlah penderita gastritis tahun 2016 sebanyak 147 orang, tahun 2017 sebanyak 130 orang dan tahun 2018 sebanyak 151 orang (Rumah Sakit Islam Siti Khadijah Palembang, 2019).

Berdasarkan latar belakang diatas peneliti tertarik untuk melakukan penelitian dengan judul "Pengalaman Penderita Gastritis Dalam Melakukan Teknik Relaksasi Nafas Dalam Untuk Membantu Menurunkan Skala Nyeri Pada Penderita Gastritis Kronis Di Rumah Sakit Islam Siti Khadijah Palembang Tahun 2019". 


\section{METODE PENELITIAN}

\section{Fokus Penelitian}

Penelitian ini difokuskan pada pengalaman penderita gastritis kronis dalam melakukan teknik relaksasi nafas dalam untuk membantu menurunkan skala nyeri pada penderita gastritis.

Teknik relaksasi nafas dalam adalah teknik yang dilakukan untuk menekan nyeri pada thalamus yang dihantarkan ke korteks cerebri dimana korteks cerebri sebagai pusat nyeri, yang bertujuan agar pasien dapat mengurangi nyeri selama nyeri timbul.Adapun hal-hal yang perlu diperhatikan saat relaksasi adalah pasien harus dalam keadaan nyaman, pikiran pasien harus tenang dan lingkungan yang tenang.Suasana yang rileks dapat meningkatkan hormon endorphin yang berfungsi menghambat transmisi impuls nyeri sepanjang saraf sensoris dari nosiseptor saraf perifer ke kornu dorsalis kemudian ke thalamus, serebri, dan akhirnya berdampak pada menurunnya persepsi nyeri (Brunner \& Suddart dalam Ayudianingsih, 2015).

\section{Data dan Teknik Pengumpulan Data Data}

Penelitian ini menggunakan data primer yang diperoleh melalui partisipan yaitu penderita gastritis kronis dalam melakukan teknik relaksasi nafas dalam untuk membantu menurunkan skala nyeri, dengan cara mewawancari pasien gastritis secara mendalam untuk mendapatkan informasi maupun keterangan-keterangan yang berkaitan dengan pengalaman penderita gastritis kronis dalam melakukan teknik relaksasi nafas dalam untuk membantu menurunkan skala nyeri pada penderita gastritis.

Data primer lain juga didapatkan dari informan kunci, mengenai prosedur yang tepat dan benar maupun keterangan lain yang dapat menjelaskan masalah tersebut diatas. Selain itu penelitian ini juga mempergunakan data sekunder yang diperoleh dari catatan-catatan rumah sakit (medrec), buku-buku bacaan, jurnal-jurnal dan studi kepustakaan lainnya.

\section{Teknik Pengumpulan Data}

Dalam proses penelitian penulis menggunakan metode pendekatan yang berkaitan dengan judul yaitu wawancara, yaitu penulis melakukan serangkaian tanya jawab secara langsung dengan penderita gastritis kronis mengenai pengalaman penderita gastritis kronis dalam melakukan teknik relaksasi nafas dalam untuk membantu menurunkan skala nyeri pada penderita gastritis.

\section{Situasi Sosial dan Sampel Penelitian Situasi Sosial}

Situasi sosial dalam penetian ini adalah 2 orang pasien gastritis kronis sebagai partisipan dan seorang informan kunci yaitu perawat yang bertugas di Rumah Sakit Islam Siti Khodijah Palembang.

Sampel

Sampel penelitian ini mempergunakan 3 orang sampel yaitu : 2 orang sebagai partisipan, dan 1 sebagai informan kunci.

Kriteria partisipan

a. Pasien gastritis kronis yang ada di Rumah Sakit Islam Siti Khodijah Palembang

b. Kooperatif dan bisa diajak berkomunikasi dengan baik

c. Bersedia menjadi partisipan dalam penelitian

Kriteria informan kunci

a. Perawat

b. Lama bekerja lebih dari 5 tahun

c. Bersedia ikut partisipasi dalam penelitian

d. Kooperatif

\section{Teknik Analisa Data}

Analisa data dalam penelitian kualitatif dilakukan saat pengumpulan data berlangsung dan setelah selesai 
pengumpulan data dalam periode tertentu. Data atau informasi yang telah diperoleh dicatat atau direkam dengan menggunakan radio kaset dan buat transkip, kemudian dipindahkan kedalam matrik dan didalam matrik data dikelompokkan sesuai dengan tujuan penelitian.

Teknik pengumpulan data dilakukan secara manual. Dengan mencatat jawaban yang diperlukan informan sebagai sumber data primer.

\section{HASIL PENELITIAN DAN PEMBAHASAN}

\section{Hasil Penelitian}

\section{Gambaran Umum Informan}

Pada penelitian ini sampel (partisipan) berjumlah 3 orang yaitu Tn. M dan Tn. K sebagai informan (pasien gastritis) dan Ny. T sebagai informan kunci (perawat) di Rumah Sakit Islam Siti Khadijah Palembang. Untuk lebih jelasnya, karakteristik informan dan informan kunci dalam penelitian ini dapat dilihat pada tabel 1. berikut ini :

Tabel 1. Karakterstik Informan Wawancara Mendalam Berdasarkan Umur, Pendidikan Dan Pekerjaan

\begin{tabular}{cccc}
\hline Inisial & Umur & Pendidikan & Pekerjaan \\
\hline Tn. M & 73 tahun & SMP & Pedagang \\
\hline Tn.K & 62 tahun & SD & Buruh \\
\hline
\end{tabular}

Sumber: Hasil pengolahan data penelitian lapangan tahun 2019

Tn.M berusia 73 tahun, pendidikan terakhir yang pernah di tempuh adalah SMP dan bekerja sebagai pedagang.Sedangkan Tn.K berusia 62 tahun, pendidikan terakhir yang pernah ditempuh adalah SD dan bekerja sebagai buruh.

Tabel 2. Karakterstik Informan Kunci Wawancara Mendalam Berdasarkan Umur, Pendidikan Dan Pekerjaan

\begin{tabular}{ccccc}
\hline Inisial & Umur & Pendidikan & Pekerjaan & Lama Bekerja \\
\hline Ny.T & 35 tahun & S1 Keperawatan & Perawat & \pm 12 tahun \\
\hline
\end{tabular}

Sumber: Hasil pengolahan data penelitian lapangan tahun 2019
Dari tabel 4.2 diatas diketahui Ny.T berusia 35 tahun, pendidikan terakhirS1 Keperawatan bekerja sebagai perawat di Rumah Sakit Islam Siti Khadijah Palembang dan sudah bekerja selama \pm 12 tahun.

\section{Pembahasan}

Berdasarkan hasil wawancara
mendalam dengan kedua diketahui bahwa kedua responden yaitu Tn.M dan Tn.K sudah sejak lama menderita penyakit gastritis, namun kedua informan tidak menghiraukan penyakitnya karena menganggapnya suatu hal yang biasa.Kedua informan juga tidak memiliki riwayat keluarga menderita penyakit gastritis.

Menurut Rendy (2012), penyakit gastritis adalah suatu peradangan permukaan mukosa lambung yang akut dengan kerusakan erosi. Gastritis adalah suatu peradangan pada mukosa lambung yang dapat bersifat akut, kronik atau lokal.

Hal yang sama dinyatakan Sukarmin (2012), yang menjelaskan bahwa gastritis merupakan peradangan yang mengenai mukosa lambung. Peradangan ini dapat mengakibatkan pembengkakan mukosa lambung sampai terlepasnya epitel mukosa superficial yang menjadi penyebab terpenting dalam gangguan saluran pencernaan. Pelepasan epitel akanmerangsang timbulnya proses inflamasi pada lambung.

Sedangkan menurut Etika (2018), menyatakan bahwa penyakit gastritis atau asam lambung naik juga bisa disebabkan oleh genetik turunan orangtua seperti yang dinyatakan oleh beberapa penelitian. Contohnya pada penelitian yang diterbitkan dalam jurnal Gastroenterology yang menjadikan anak kembar sebagai pesertanya. Dari hasil penelitian diketahui kalau sebanyak $43 \%$ penyakit asam lambung yang dialami peserta dipengaruhi oleh adanya kode genetik bawaan dari orangtua mereka, yang juga memiliki penyakit tersebut. 
Berdasarkan hasil wawancara mendalam dengan kedua responden yaitu Tn.M dan Tn.K menjelaskan bahwa kedua informan sering mengalami kekambuhan penyakit gastritis, hal tersebut dialami kedua informan ketika telat makan dan ketika perut kosong.

Hal ini sesuai dengan pernyataan informan kunci yang menyatakan bahwa "Gejalanya itu ya...nyeri lambung yang disebabkan dari telat makan itu tadi”.

Menurut Samiadi (2018), menjelaskan bahwa ketika lambung dibiarkan kosong dalam waktu lama, cairan asam yang menggenang akan menyebabkan dinding lambung teriritasi dan meradang. Ini yang menjadi pemicu atau yang memperburuk gejala maag Anda. Dengan menerapkan pola makan yang teratur, pencernaan akan bekerja lebih baik dan efisien.

Sedangkan menurut Widyatama (2017), menjelaskan bahwa pola makan yang tidak teratur, termasuk telat makan, juga dapat memicu terjadinya produksi enzim-enzim pencernaan yang tidak memadai. Kondisi tersebut dapat menghambat proses pencernaan. Ketika proses pencernaan tidak berjalan dengan lancar, gejala mag juga dapat muncul.

Berdasarkan hasil wawancara mendalam dengan kedua responden yaitu Tn.M dan Tn.K menjelaskan bahwa saat penyakitnya kambuh kedua informan merasakan rasa nyeri dan sakit pada daerah lambung hingga ke pinggang.

Menurut Rendy (2012), tanda dan gejala gastritis antara lain mual, sebagian penderita bisa muntah darah, nyeri epigastrium, nausea, muntah dan cegukan serta sakit kepala. Sedangkan gejala gastritis akut adalah nyeri epigastrium, mual, kembung muntah, dapat ditemukan hematemesis dan melena. Dan gejala gastritis kronis adalah kebanyakan tidak mempunyai keluhan, hanya sebagai mengeluh nyeri ulu hati, anoreksia, nausea.
Berdasarkan hasil wawancara mendalam dengan kedua responden yaitu Tn.M dan Tn.K menjelaskan bahwa selama menderita penyakit gastritis kedua informan telah melakukan pengobatan baik kedokter maupun ke puskesmas dan telah mengkonsumsi obat-obatan. Selain itu kedua informan juga diajarkan untuk melakukan terapi non farmakologi seperti relaksasi nafas dalam dan kompres air hangat untuk mengurangi rasa nyeri ketika penyakitnya kambuh.

Hal ini sesuai dengan pernyataan informan kunci yang menyatakan bahwa "Untuk mengatasinya itu bisa makan dengan porsi sedikit tapi sering kemudian dapat juga dilakukan dengan kompres panas, dan relaksasi nafas dalam".

Kami juga pernah, kalau dia lagi kambuh kan kita ajarkan teknik relaksasi nafas dalam misalkan dia sedang merasakan nyeri sekali. Iya dek sering di sini kalau pasiennya lagi nyeri-nyeri kita ajarkan teknik relaksasi nafas dalam dan kompres panas.

Menurut Kurnia (2009), beberapa cara untuk mengobati gastritis yaitu: 1) Untuk menurunkan asam lambung bisa menggunakan obat-obat maag yang dijual bebas. Tapi pengobatan tersebut hanya berlansung sementara karena proses penyembuhan luka lambung berlansung lama. Walaupun luka tersebut sudah pulih, namun akan meninggalkan jaringan parut yang mudah sobek apabila terjadi iritasi karena produksi asam lambung yang berlebihan hingga mengakibatkan sekresi kelenjar-kelenjar lambung tidak seimbang. 2) Istirahat yang cukup sampai gejala gastritis mereda. 3) Sebisa mungkin mengolah tekanan emosional dan selama proses pemulihan kurangi kerja berat. 4) Mengkonsumsi makanan yang lunak. 5) Ramuan tradisional berupa kunyit bisa juga menyembuhkan luka dinding lambung. 6) Periksakan ke dokter jika penyakit maag terus menerus kambuh karena siapa tahu penyakit tersebut disebabkan oleh bakteri. 
Menurut Lusiana (2015), Intervensi Non Farmakologiyang dapat digunakan untuk mengatasi nyeri adalah Stimulasi dan massase kutaneus, stimulasi kulit, transcutaneous elecrical nerve stimulation (TENS), distraksi, teknik relaksasi, imajinasi terbimbing, hipnosis, metoda bedah-neuro.

Berdasarkan hasil wawancara mendalam dengan kedua responden yaitu Tn.M dan Tn.K menjelaskan bahwa setelah melakukan teknik relaksasi nafas dalam kedua informan merasa lega, dan nyeri yang dirasakan sedikit berkurang.

Hal ini sesuai dengan pernyataan informan kunci yang menyatakan bahwa "Biasanya dia merasakan lebih tenang, lebih nyaman....kemudian nyerinya juga berkurang”

Menurut Smelzer dalam Hermanto (2013), menjelaskan tujuan teknik relaksasi napas dalam adalah untuk meningkatkan ventilasi alveoli, memelihara pertukaran gas, mencegah atelektasi paru, meningkatkan efesiensi batuk, mengurangi stress baik stress fisik maupun emosional yaitu menurunkan intensitas nyeri dan menurunkan kecemasan. Sedangkan manfaat yang dapat dirasakan oleh klien setelah melakukan teknik relaksasi nafas dalam adalah dapat menghilangkan nyeri, ketenteraman hati, dan berkurangnya rasa cemas.

Berdasarkan hasil wawancara mendalam dengan kedua responden yaitu Tn.M dan Tn.K menjelaskan bahwa perawat telah mengajarkan kepada kedua informan dalam melakukan teknik relaksasi nafas dalam, dan kedua informan telah melakukan teknik relaksasi nafas dalam tersebut sejak lama. Menurut kedua informan setelah melakukan teknik relaksasi nafas dalam tersebut perasaan menjadi lega dan rasa nyeri yang dirasakan semakin berkurang.

Hal ini sesuai dengan pernyataan informa kunci yang menyatakan bahwa "Pernah, kalo dio lagi kambuh kan kito ajarkan teknik relaksasi nafas dalam misalke dio lagi nyeri nian". "Iyo dek sering di sini kalo pasiennyo lagi nyerinyeri kito ajarke teknik relaksasi nafas dalam, kompres panas"

Smeltzer dan Bare (2002), menyatakan bahwa tujuan relaksasi pernafasan adalah untuk meningkatkan ventilasi alveoli, memelihara pertukaran gas, mencegah atelektasi paru, merilekskan tegangan otot, meningkatkan efesiensi batuk, mengurangi stress baik stress fisik maupun emosional yaitu menurunkan intensitas nyeri (mengontrol atau mengurangi nyeri) dan menurunkan kecemasan.

Berdasarkan hasil wawancara mendalam dengan kedua responden yaitu Tn.M dan Tn.K menjelaskan bahwa dalam melakukan teknik relaksasi nafas dalam kedua informan selalu mengulang-ulang teknik relaksasi nafas dalam tersebut sampai nyeri lambung yang dirasakannya berkurang dan kedua informan merasa lega.

Hal ini sesuai dengan pernyataan informan kuci yang menyatakan bahwa "Tujuannya itu untuk mengurangi rasa nyeri pada pasien yang menderita gastritis".

Menurut Aningsih (2018), menjelaskan bahwa teknik relaksasi nafas dalam adalah bernafas dengan perlahan dan menggunakan diafragma, sehingga memungkinkan abdomen terangkat perlahan dan dada mengembang penuh. Dalam teknik ini merupakan suatu bentuk asuhan keperawatan, bagaimana perawat mengajarkan cara melakukan teknik relaksasi nafas dalam, nafas lambat (menahan inspirasi secara maksimal) dan bagaimana menghembuskan nafas secara perlahan, selain dapat menurunkan intensitas nyeri, teknik relaksasi nafas dalam juga dapat meningkatkan ventilasi paru dan meningkatkan oksigenasi darah. Selain itu manfaat yang didapat setelah melakukan teknik relaksasi nafas dalam adalah mengurangi atau bahkan menghilangkan rasa nyeri yang terjadi pada individu tersebut, ketentraman hati, dan 
berkurangnya rasa cemas, juga praktis dalam melakukan teknik relaksasi nafas dalam tersebut tanpa harus mengeluarkan biaya.

Berdasarkan hasil wawancara mendalam dengan kedua responden yaitu Tn.M dan Tn.K menjelaskan bahwa pada saat melakukan teknik relaksasi nafas dalam posisi badan kedua informan Tn.M sambil duduk sedangkan posisi Tn.K dilakukan sambil duduk dan berbaring.

Ada beberapa posisi relaksasi nafas dalam yang dapat dilakukan menurut (Smeltzer \& Bare, 2002) : a) Posisi relaksasi dengan terlentang Berbaring terlentang, kedua tungkai kaki lurus dan terbuka sedikit, kedua tangan rileks disamping bawah lutut dan kepala diberi bantal. b) Posisi relaksasi dengan berbaring miring Berbaring miring, kedua lutut ditekuk, dibawah kepala diberi bantal dan dibawah perut sebaiknya diberi bantal juga, agar perut tidak menggantung. c) Posisi relaksasi dalam keadaan berbaring terlentang Kedua lutut ditekuk, berbaring terlentang, kedua lutut ditekuk, kedua lengan disamping telinga. d) Posisi relaksasi dengan duduk Duduk membungkuk, kedua lengan diatas sandaran kursi atau diatas tempat tidur, kedua kaki tidak boleh menggantung.

Berdasarkan hasil wawancara mendalam dengan kedua responden yaitu Tn.M dan Tn.K menjelaskan bahwa pada saat melakukan teknik relaksasi nafas dalam kedua informan melakukannya di lokasi yang sepi dan sunyi dengan tujuan agar lebih mudah berkonsentrasi. Berdasarkan hasil wawancara mendalam dengan kedua responden yaitu Tn.M dan Tn.K menjelaskan bahwa Tn.M biasa melakukan teknik relaksasi nafas dalam dengan menarik nafas dari hidung dan menahannya selama 2-3 detik kemudian dihembuskan dari mulut secara perlahan-lahan. Sedangkan Tn.K menarik nafas dalam tanpa ada hitungan dan kemudian menghembuskannya melalui mulut secara perlahan-lahan. Berdasarkan hasil wawancara mendalam dengan kedua responden yaitu Tn.M dan Tn.K menjelaskan bahwa kedua informan melakukan teknik relaksasi nafas dalam sekitar 5 sampai 10 menit atau hingga nyeri yang dirasakan berkurang.

Prosedur teknik relaksasi nafas dalam menurut Priharjo (2003), yakni dengan bentuk pernapasan yang digunakan pada prosedur ini adalah pernapasan diafragma yang mengacu pada pendataran kubah diagfragma selama inspirasi yang mengakibatkan pembesaran abdomen bagian atas sejalan dengan desakan udara masuk selama inspirasi. Adapun langkah-langkah teknik relaksasi nafas dalam adalah sebagai berikut : 1) Ciptakan lingkungan yang tenang 2) Usahakan tetap rileks dan tenang 3) Menarik nafas dalam dari hidung dan mengisi paru-paru dengan udara melalui hitungan 1,2,3. 4) Perlahan-lahan udara dihembuskan melalui mulut sambil merasakan ekstrimitas atas dan bawah rileks 5) Anjurkan bernafas dengan irama normal 3 kali 6) Menarik nafas lagi melalui hidung dan menghembuskan melalui mulut 7) Anjurkan untuk mengulangi prosedur hingga nyeri terasa berkurang 8) Ulangi sampai 15 kali, dengan selingi istirahat singkat setiap 5 kali.

Berdasarkan hasil wawancara mendalam dengan kedua responden yaitu Tn.M dan Tn.K menjelaskan bahwa selama menggunakan teknik relaksasi nafas dalam kedua informan merasakan manfaat yaitu nyeri perut berangsur-angsur berkurang. Kedua responden jugamenjelaskan bahwa tujan kedua informan melakukan teknik relaksasi nafas dalam adalah untuk mengurangi rasa nyeri.

Menurut Kusyati (2015), manfaat teknik relaksasi nafas dalam diantaranya adalah : Ketentraman hati, berkurangnya rasa cemas, khawatir dan gelisah, tekanan dan ketegangan jiwa menjadi rendah, detak jantung lebih rendah, mengurangi tekanan darah, ketahanan yang lebih besar terhadap penyakit, tidur lelap, kesehatan mental menjadi lebih baik, daya ingat lebih baik, meningkatkan daya berpikir logis, 
meningkatkan kreativitas, meningkatkan keyakinan, meningkatkan daya kemauan, intuisi.

Berdasarkan hasil wawancara mendalam dengan kedua responden yaitu Tn.M dan Tn.K menjelaskan bahwa selain melakukan teknik relaksasi napas dalam Tn.M juga melakukan terapi kompres air hangat dengan menggunakan botol. Sedangkan Tn.K hanya melakukan terapi relaksasi nafas dalam dan tiduran atau istirahat.

Menurut Pahlevi (2017), saat ini marak dikembangkan terapi tambahan untuk mengatasi nyeri, seperti: kompres hangat / dingin, latihan nafas dalam, musik, aromatherapi, imajinasi terbimbing dan hipnosis.

Menurut Potter \& Perry dalam Ayudianingsih (2015), manajemen nyeri merupakan salah satu carayang digunakan dibidang kesehatan untuk mengatasi nyeri yang dialami oleh pasien. Pemberian analgesik biasanya dilakukan untuk mengurangi nyeri. Teknik relaksasi merupakan alternatif non obat-obatan dalam strategi penanggulangan nyeri, disamping metode TENS (Transcutaneons Electric Nerve Stimulation), biofeedack, plasebo dan distraksi. Relaksasi merupakan kebebasan mental dan fisik dari ketegangan dan stress, karena dapat mengubah persepsi kognitif dan motivasi afektif pasien. Teknik relaksasi membuat pasien dapat mengontrol diri ketika terjadi rasa tidak nyaman atau nyeri, stress fisik dan emosi pada nyeri.

Berdasarkan hasil wawancara mendalam dengan kedua responden yaitu Tn.M dan Tn.K menjelaskan bahwa setiap kedua informan melakukan teknik relaksasi nafas dalam nyeri yang ia rasakan berangsur berkurang.

Menurut Kusyati (2015), manfaat teknik relaksasi nafas dalam diantaranya adalah : Ketentraman hati, berkurangnya rasa cemas, khawatir dan gelisah, tekanan dan ketegangan jiwa menjadi rendah, detak jantung lebih rendah, mengurangi tekanan darah, ketahanan yang lebih besar terhadap penyakit, tidur lelap, kesehatan mental menjadi lebih baik, daya ingat lebih baik, meningkatkan daya berpikir logis, meningkatkan kreativitas, meningkatkan keyakinan, meningkatkan daya kemauan, intuisi.

Hasil penelitian ini sejalan dengan penelitian Rampengan (2014) yang berjudul pengaruh teknik relaksasi dan teknik distraksi terhadap perubahan intensitas nyeri pada pasien post operasi di Ruang Irina A Atas RSUP Prof. Dr.R.D Kandou Manado. Hasil penelitian terhadap 15 responden sebelum dilakukan teknik relaksasi didapatkan hasil sebagian besar responden mengalami intensitas nyeri lebih nyeri yaitu sebanyak 6 orang $(40 \%)$, intensitas nyeri sedikit lebih nyeri sebanyak 4 orang $(26,7 \%)$, intensitas nyeri sangat nyeri 3 orang $(20 \%)$ dan intensitas nyeri sedikit nyeri sebanyak 2 orang $(13,3 \%)$. Setelah dilakukan teknik relaksasi, sebanyak 2 responden menyatakan tidak mengalami nyeri dan tidak ada responden yang mengalami intensitas nyeri sangat nyeri dan intensitas nyeri lebih nyeri.

Hasil penelitian ini juga sejalan dengan penelitian Putri (2017) yang berjudul relaksasi nafas dalam untuk mengurangi nyeri pada pasien dengan gastritis. Berdasarkan hasil pengkajian yang telah dilakukan pada keluara Tn. J Khususnya pada Ny.S Tanda gejala yang muncul adalah Ny. S Mengatakan nyeri perut, mual, muntah.Ny. S mulai merasakan gejala-gejala kalau sakit sejak 1 tahun yang lalu. setelah dibawa periksa ke dokter Ny. S dianjurkan untuk mengurangi makan makanan yang pedas, pada bulan Februari 2016 nyeri perut itu kambuh Ny.S Mengalami perlukaan lambung karena memakan makanan yang pedas kemudian terjai nyeri perut, mual, muntah yang menyebabkan asam lambung nya meningkat. Intervensi yang dilakukan adalah mengajarkan relaksasi nafas dalam untuk mengatasi nyeri perut selain itu $\mathrm{Ny}$. S juga diajarkan tentang guide imagery untuk 
mengatai nyeri perut dan juga cemas yang dirasakan. Implementasi dilakukan selama 3 hari mulai tanggal 19 februari sampai tanggal 21 februari 2017. pada tanggal 19 februari 2017 dilakukan relaksasi nafas dalam untuk menatasi nyeri perut $\mathrm{Ny}$. sebelum menajarkan relaksasi nafas dalam didapatkan hasil bahwa keluara hanya menyuruh Ny. S untuk berbaring kemudian setelah itu diajarkan tentang relaksasi nafas dalam yang membutuhkan suasana rumah yang nyaman dan tenang.

Berdasarkan hasil penelitian dan pembahasan diatas peneliti berasumsi bahwa teknik relaksasi nafas dalam efektif dalam membantu menurunkan skala nyeri pada penderita gastritis. Dengan melakukan relaksasi nafas dalam dapat membuat pasien menjadi rileks, tenang, nyaman serta mengurangi rasa nyeri. Suasana yang rileks dapat meningkatkan hormon endorphin yang berfungsi untuk mengurangi rasa nyeri.

\section{KESIMPULAN}

Berdasarkan hasil penelitian yang telah dilakukan di Rumah Sakit Islam Siti Khadijah Palembang, dapat disimpulkan bahwa :

Pengalaman responden selama melakukan terapi relaksasi nafas dalam Tn.M dan Tn.K mengaku nyeri lambung yang dirasakan berangasur-angsur berkurang.Tn.M dan Tn.K melakukan terapi relaksasi nafas dalam setiap kali nyeri lambungnya kambuh. Dari penjelasan kedua informan diketahui bahwa teknik relaksasi dilakukan pada posisi duduk dan berbaring dalam suasana yang tenang.Kedua informan menarik nafas dalam dan menghembuskannya secara perlahan melalui mulut.

\section{SARAN}

\section{Bagi STIKES Mitra Adiguna Palembang}

Diharapkan dapat lebih melengkapi referensi seperti buku-buku sumber, majalah kesehatan, jurnal, serta bahan- bahan yang menunjang penulisan Karya Tulis Ilmiah ini guna meningkatkan mutu pendidikan, menyarankan agar mahasiswa sebelum menentukan judul sebaiknya menentukan masalah yang layak dan relevan untuk diteliti.

2. Bagi Rumah Sakit Islam Siti Khadijah Palembang

Diharapkan kepada petugas kesehatan di Rumah Sakit Islam Siti Khadijah Palembang, dapat meningkatkan pelayanan kepada pasien gastritis khususnya dalam membantu pasien mengatasi rasa nyeri. Dalam menurunkan skala nyeri pada pasien gastritis selain menggunakan pengobatan farmakologi yang telah diterapkan selama ini diharapkan dapat menggunakan alternatif pengobatan non farmakologi seperti memberikan kompres air hangat kepada pasien gastritis.

\section{Bagi Peneliti Selanjutnya}

Diharapkan peneliti selanjutnya dapat mencari alternatif lain dalam menurunkan skala nyeri pasien gastritis seperti memberikan massase atau kompres hangat pada pasien gastritis serta dengan menggunakan metode penelitian kualitatif sehingga penelitian tentang penurunan skala nyeri pada pasien gastritis dapat terus di kembangkan.

\section{DAFTAR PUSTAKA}

Angkow, Julia. 2016. Faktor-faktor yang berhubungan dengan kejadian gastritis di Wilayah Kerja Puskesmas Bahu Kota Manado. Jurnal Keperawatan Fakultas Kedokteran Universitas Sam Ratulangi Manado.

Ayudianingsih. 2015. Pengaruh teknik relaksasi nafas dalam terhadap 
penurunan tingkat nyeri pada pasien pasca operasi fraktur femur di Rumah Sakit Karima Utama Surakarta. Jurnal FIK UMS Kartasura

Bare \& Smeltzer. 2002. Buku Ajar Keperawatan Medikal Bedah Brunner \&. Suddart (Alih bahasa Agung Waluyo) Edisi 8 vol.3. Jakarta : EGC

Bruner \& Sudart. 2007. Buku Ajar Keperawatan Medikal Bedah, Vol. 2, Edisi 9, EGC, Jakarta

Endang. 2008. Gangguan Saluran Pencernaan. Jakarta : EGC

Fahrur. 2009. Disiplin Waktu Tuntaskan Maag.

http://www.ngobrolaja.com/showthre ad.php, diakses 15 Januari 2019 dari

Hidayat, A Aziz Alimun. 2009. Metode Penelitian Keperawatandan Teknik Analisis Data. Jakarta: Salemba medika.

Kurnia,H. 2009. Kiat Jitu Tangkal Penyakit Orang Kantoran. Yagyakarta : Best Publisher

Lusiana. 2015. Prosedur Keperawatan. Yogyakarta : TIM

Notoatmodjo, S. 2012. Metodologi Penelitian Kesehatan. Jakarta : PT. Rineka Cipta.

Putri, Rona Sari Mahaji. 2017. Hubungan pola makan dengan timbulnya gastritis pada pasien di Universitas Muhammadiyah Malang Medical Centre (UMC). Jurnal Keperawatan Universitas Tibhuwana Tunggadewi Malang.
Rampengan. 2014. Pengaruh teknik relaksasi dan teknik distraksi terhadap perubahan intensitas nyeri pada pasien post operasi di Ruang Irina A Atas RSUP Prof. Dr. R. D. Kandou Manado. Jurnal Universitas Sam Ratulangi

Rendy, Clevo dan Margareth. 2012. Asuhan keperawatan medikal bedah penyakit dalam. Yogyakarta : Nuhamedika

Rumah Sakit Islam Siti Khadijah. 2019. Jumlah penderita gastritis. Palembang.

Saparwati, Mona. 2012. Studi Fenomenologi : Pengalaman Kepala Ruang dalam Mengelola Ruang Rawat di RSUD Ambarawa. Tesis Magister Ilmu Keperawatan Universitas Indonesia, Depok.

Saydam, Gouzali. (2011). Memahami Berbagai Penyaki t: Penyakit Pernafasan dan Gangguan Pencernaan. Bandung: Alfabeta

Sugiyono. 2009. Metode Penelitian Kuantitatif dan Kualitatif. Bandung

Sukarmin, S.Kep. Ns. 2012. Keperawatan Pada System Pencernaan. Celemba Timur : Pustaka Pelajar.

Tussakinah. 2017. Hubungan pola makan dan stres terhadap kekambuhan gastritis di Wilayah Kerja Puskesmas Tarok Kota Payakumbuh. Jurnal kesehatan Andalas. 